\title{
Coronary artery calcium score plays an important role for cardiovascular risk stratification in the statin benefit groups of asymptomatic individuals
}

\author{
Dong-Hyeon Lee ${ }^{1}$, Ho-Joong Youn ${ }^{1 *}$, Hae-Ok Jung ${ }^{1}$, Kiyuk Chang ${ }^{1}$, Yun-Seok Choi ${ }^{1}$ and Jung Im Jung ${ }^{2}$
}

\begin{abstract}
Background: The purpose of this study was to describe and analyze the relationship between statin benefit groups based on statin-intensity class of drugs and coronary artery calcium score (CACS) using multidetector computed tomography (MDCT) in an asymptomatic Korean population.

Methods: A total of 3914 asymptomatic individuals (mean age: $55 \pm 10$ years; male: female $=2649$ : 1265) who underwent MDCT for health examination between January 2009 and December 2012 were retrospectively enrolled. They were categorized into three groups based on statin-intensity class of drugs (high-intensity $(n=1284,32.8 \%)$; moderate-intensity ( $n=1602,40.9 \%)$ and low-intensity ( $n=931,23.8 \%)$ statin therapy groups) according to the American College of Cardiology (ACC)/American heart Association (AHA) 2013 guideline and the relationship between CACS and statin benefit group was analyzed. The statin benefit group was defined as individuals who should be considered moderate- and high-intensity statin therapy.

Results: Ten-year atherosclerotic cardiovascular disease (ASCVD; $12.6 \pm 5.3 \%$ vs. $2.9 \pm 1.9 \%, p<0.001$ ) and CACS (98 \pm 270 vs. $3 \pm 2, p<0.001$ ) were significantly higher in the high-intensity group compared to the moderateintensity statin therapy group. In the high-intensity statin therapy group, age [odds ratio: $1.299(1.137-1.483), p<0.001$, male gender [odds ratio: 44.252 (1.959-999.784), $p=0.001$ ], and fasting blood glucose [odds ratio: 1.046 (1.007-1.087), $p=0.021]$ were independent risk factors associated with CACS $\geq 300$ on multivariate logistic regression analysis.

Conclusions: CACS on MDCT might be an important complementary tool for cardiovascular disease risk stratification. This study indicates that individualization of statin therapy as well as lifestyle modification will be useful in asymptomatic individuals, especially those in whom high-intensity statin therapy is required.
\end{abstract}

Keywords: Coronary artery, Calcium, Computed tomography, Statins, Primary prevention

\section{Background}

Although several large-scale epidemiological studies including the Framingham Heart Study have shown the importance of a balanced diet and regular exercise in maintaining good health, differences in cardiovascular risk factors between men and women and the detrimental effects of cigarette smoking are significant factors in

\footnotetext{
* Correspondence: younhj@catholic.ac.kr

${ }^{1}$ Division of Cardiology, Department of Internal Medicine, Seoul St. Mary's Hospital, The Catholic University of Korea, \#505 Banpo-dong, Seocho-gu, Seoul 137-701, South Korea

Full list of author information is available at the end of the article
}

the development of coronary heart disease (CHD), leading to angina pectoris, myocardial infarction (MI) and death [1]. However, there are some limitations in the estimation of cardiovascular morbidity and mortality risk, such as a possible overestimation in a low-risk population or underestimation in a high-risk population $[2,3]$.

The most recent guidelines were published in 2013 by the American College of Cardiology (ACC) and the American heart Association (AHA), and addressed the prevention of cardiovascular diseases (CVD) by better assessing cardiovascular risks and the treatment of blood cholesterol $[4,5]$. Furthermore, these guidelines emphasized that more 
accurately identifying higher risk individuals for administration of focused statin therapy may improve the likelihood of benefit for those individuals $[4,5]$.

While screening for coronary artery calcium score (CACS) using multidetector computed tomography (MDCT) is not currently recommended for asymptomatic patients who are low risk (0 to 1 risk factor or a 10year risk $<10 \%$ ) or high risk (CHD risk equivalent or a 10 -year risk $>20 \%$ ) according to the Framingham criteria, it may be useful in patients with intermediate risk (more than two risk factors or a 10-year risk of 10-20\%) $[6,7]$. CACS has an excellent negative predictive value for excluding the presence of significant coronary artery disease $[8,9]$. It also provides more important prognostic information for cardiovascular risk stratification than biomarkers like C-reactive protein $[10,11]$. Therefore, CACS may play a role in patient management and the prediction of cardiovascular event incidence.

Little information is available on the relationship between CACS and the statin-intensity class of drugs in asymptomatic healthy individuals according to the 2013 ACC/AHA Guideline on the Assessment of Cardiovascular Risk and on the Treatment of Blood Cholesterol to Reduce Atherosclerotic Cardiovascular Risk in Adults [4, 5]. The purpose of this study was to describe and analyze the relationship between statin benefit groups based on statin-intensity class of drugs and CACS using MDCT in an asymptomatic Korean population according to the ACC/AHA 2013 guideline.

\section{Methods}

\section{Study population and protocol}

Between January 2009 and December 2012, a total of 3914 asymptomatic individuals (mean age: $55 \pm 10$ years; male: female $=2649:$ 1265) who underwent MDCT during a health check-up at the Health Promotion Center of Seoul St. Mary's Hospital (The Catholic University, Seoul, Korea) were retrospectively enrolled.

The presence or absence of variable data (i.e., hypertension, diabetes, dyslipidemia, family history of cerebrovascular accident and smoking status) was defined as indicated above [12]. All data were obtained via questionnaire.

According to the ACC/AHA 2013 guideline, individuals who met the following criteria were included in the statin benefit groups based on statin-intensity class of drug: (i) clinical ASCVD; (ii) primary elevations in lowdensity lipoprotein cholesterol (LDL-C) $\geq 190 \mathrm{mg} / \mathrm{dL}$; (iii) 40 to 75 years of age with diabetes with LDL-C 70$189 \mathrm{mg} / \mathrm{dL}$; and (iv) an estimated 10-year ASCVD risk of $7.5 \%$ or higher $[4,5]$.

Exclusion criteria were as follows: the (i) prior coronary artery bypass graft $(n=4,0.1 \%)$; (ii) prior percutaneous coronary intervention using stents $(n=39,1.0 \%)$, (iii) irregular heartbeat (e.g., atrial fibrillation; $n=33$,
$0.8 \%$ ); (iv) very severe obesity (body mass index $\geq 40 \mathrm{~kg} /$ $\left.\mathrm{m}^{2} ; n=9,0.2 \%\right)$; or (v) inability to comply with breath holding instructions $(n=12,0.3 \%)$. There were no patients with NYHA class II-IV ischemic systolic heart failure or with hemodialysis.

This study was approved by the Institutional Review Committee of St Mary's Hospital, the Catholic University of Korea and was conducted in agreement with the Declaration of Helsinki (KC17RESE0408).

\section{Anthropometric parameter measurement}

Each participant underwent a complete physical examination including anthropometric measurements. Height was measured to the nearest $0.1 \mathrm{~cm}$ with a portable stadiometer (InBody 720; Biospace Ltd., Seoul, Korea) and body weight was measured to the nearest $0.1 \mathrm{~kg}$ using a digital scale while patients were wearing a standardized health check-up gown. Body mass index was calculated as weight in kilograms divided by height in meters squared. Waist circumference was measured using a standardized tape by the same well-trained staff. Waist circumference was measured 1 inch above the umbilicus in a standing position. Systolic blood pressure (BP), diastolic BP and heart rate were measured using an automatic sphygmomanometer (BP203RV-II; Nippon Colin, Komaki, Japan) with subjects in a seated position after quietly resting for $10 \mathrm{~min}$.

\section{Biochemical and hematologic parameter analysis assays}

Fasting blood samples were taken the day of routine health check-up; $10 \mathrm{~mL}$ of blood was taken and mixed with ethylenediaminetetraacetic acid to prevent clotting. Plasma was obtained by centrifugation, frozen in liquid nitrogen and stored at $-80{ }^{\circ} \mathrm{C}$ until further analysis.

The lipid profile, including total cholesterol, triglyceride, high-density lipoprotein cholesterol (HDL-C) and LDL-C levels, was measured using an enzymatic method by an automatic analyzer (7600-210; Hitachi Medical Corp., Tokyo, Japan). HbA1c was measured using a G8 HbA1c analyzer (Tosoh Corporation, Tokyo, Japan). Biochemistry including fasting blood glucose and C-reactive protein were measured using a biochemistry analyzer (7600-210; Hitachi Medical Corp., Tokyo, Japan).

\section{Ten-year atherosclerotic cardiovascular disease (ASCVD) risk}

According to the 2013 ACC/AHA Guideline on the Assessment of Cardiovascular Risk and on the Treatment of Blood Cholesterol to Reduce Atherosclerotic Cardiovascular Risk in Adults [4, 5], 10-year ASCVD risk was defined in men and women between 40 and 79 years of age as the risk of developing a first ASCVD event (nonfatal MI or death from CHD, or fatal or nonfatal stroke) 
over a 10-year period in those free from ASCVD at the beginning of the period.

\section{Statin benefit groups based on statin-intensity class of drugs}

As mentioned above, all participants $(n=3817$ : mean age: $55 \pm 10$ years; range 40 to 79 years) in this study were categorized into three lipid-lowering drug therapy groups based on statin-intensity class of drugs according to the 2013 ACC/AHA guideline $[4,5]$ used in randomized controlled trials reviewed by an expert panel: (i) high-intensity statin therapy group ( $n=1284,32.8 \%)$, defined as a daily dose that lowers LDL-C by at least $50 \%$ (absolute benefit of statin therapy or absolute-risk reduction for ASCVD); (ii) moderate-intensity statin therapy group ( $n=1602,40.9 \%$ ), defined as a daily dose that lowers LDL-C by 30 to $49 \%$ (relative benefit of statin therapy or relative-risk reduction for ASCVD); and (iii) low-intensity statin therapy group ( $n=931,23.8 \%)$, defined as a daily dose that lowers LDL-C by less than $30 \%$ (no net benefit from statin therapy over a 10 -year period). The statin benefit group was defined as individuals who should be considered moderate- and highintensity statin therapy.

\section{Measurement of CACS using MDCT}

We measured CACS using MDCT (SOMATOM Definition; Siemens Healthcare, Forchheim, Germany). Heart rate ranged from 43 to $75 \mathrm{bpm}$ (mean, $67 \mathrm{bpm}$ ) during CT acquisition. Participants did not receive any additional premedication, such as $\beta$-blockers for heart rate control. Dual-source CT parameters were as follows: tube voltage $=120 \mathrm{kVp}$, gantry rotation time $=0.33 \mathrm{~s}$, slice collimation $=64 \times 0.6 \mathrm{~mm}$, reconstruction slice width $=0.75 \mathrm{~mm}$, reconstruction slice interval $=0.4 \mathrm{~mm}$, kernel $=$ B26f, field of view $=25 \mathrm{~cm}$. Eighty milliliters of contrast agent was intravenously injected at $5 \mathrm{~mL} / \mathrm{s}$ (Iohexol, IOBRIX INJ 300; Tae Joon Pharm. Ind. Co., Ltd., Seoul, Korea) using a dual-head power injector (CT Stellant; Medrad Inc., Indianola, PA, USA). Then, $50 \mathrm{~mL}$ of saline solution chaser were injected at $5 \mathrm{~mL} / \mathrm{s}$.

All post-processing examinations were performed using retrospective electrocardiogram gating. Scans were analyzed by consensus of two observers with more than 3 years of experience in MDCT imaging (YS Choi and JI Jung). CACS for vascular calcification were analyzed using syngo.CT CaScoring software (Siemens Healthcare; Forcheim, Germany).

Agatston score, standard parameter, was used as the product of the area of calcification per coronary tomographic segment and a factor rated 1 through 4 dictated by the maximal calcium $x$-ray density in that segment to define the quantity of coronary calcium, as described elsewhere [13]. The sum of all lesion scores for each major coronary artery was used including left main, left anterior descending artery, left circumflex artery and right coronary artery to generate the total CACS. Additionally, the volume score in cubic millimeters was used as a continuous parameter.

Of the participants with two statin benefit groups requiring more than moderate-intensity statin therapy ( $n=2886,73.7 \%)$, the obtained CACS values were classified into six categories: 0 , normal $(n=1774,45.3 \%)$; $1-$ 10 , minimal $(n=322,8.2) ; 11-100$, mild $(n=494$, $12.6 \%) ; 101-400$, moderate $(n=195,5.0 \%)$; 401-1000, severe $(n=76,1.9 \%)$ and $>1000$, very severe $(n=25$, $0.6 \%)[6-8,13]$.

\section{Statistical analysis}

All data are expressed as mean \pm standard deviation for continuous variables and as a frequency percentage for categorical variables. Analysis of among the three statin benefit groups based on statin-intensity class of drugs according to the ACC/AHA 2013 guideline was performed using the analysis of variance test for continuous variables and Tukey's $b$-test as a post-hoc $t$-test for categorical data. Between the two more than moderateintensity statin therapy benefit groups, clinical variables related to CACS using MDCT were assessed based on Pearson's correlation coefficient. To identify independent factors associated with CACS $\geq 300$, we used multiple logistic regression analysis and calculated odds ratios and 95\% confidence intervals. All statistical tests were 2tailed and $p$-values $<0.05$ were considered statistically significant.

\section{Results}

\section{Clinical characteristics}

The baseline clinical and laboratory findings among the three statin benefit groups based on statin-intensity class of drugs according to the ACC/AHA 2013 guideline are summarized in Table 1.

\section{Comparison of two statin benefit groups based on the statin-intensity class of drugs}

All laboratory findings mentioned below were significantly higher in the high-intensity statin therapy group than in the moderate-intensity statin therapy group: age $(58 \pm 8$ years vs. $53 \pm 8$ years, $p<0.001)$; body mass index $\left(25.4 \pm 3.0 \mathrm{~kg} / \mathrm{m}^{2}\right.$ vs. $\left.24.6 \pm 3.6 \mathrm{~kg} / \mathrm{m}^{2}, p<0.001\right)$; waist circumference $(90 \pm 9 \mathrm{~cm}$ vs. $87 \pm 9 \mathrm{~cm}$, $p<0.001)$; systolic BP $(128 \pm 14 \mathrm{mmHg}$ vs. $122 \pm 13 \mathrm{mmHg}, p<0.001)$; diastolic BP $(77 \pm 10 \mathrm{mmHg}$ vs. $72 \pm 9 \mathrm{mmHg}, p<0.001)$; and plasma total cholesterol $(209 \pm 39 \mathrm{mg} / \mathrm{dL}$ vs. $201 \pm 32 \mathrm{mg} / \mathrm{dL}, p<0.001)$; triglyceride $(141 \pm 86 \mathrm{mg} / \mathrm{dL}$ vs. $106 \pm 75 \mathrm{mg} / \mathrm{dL}$, $p<0.001)$; LDL-C $(130 \pm 35 \mathrm{mg} / \mathrm{dL}$ vs. $122 \pm 28 \mathrm{mg} / \mathrm{dL}$, $p<0.001)$; fasting blood glucose $(105 \pm 28 \mathrm{mg} / \mathrm{dL}$ vs. 
Table 1 Baseline clinical characteristics

\begin{tabular}{|c|c|c|c|c|}
\hline Total $=3817$ & $\begin{array}{l}\text { Low-intensity statin therapy } \\
(n=931)\end{array}$ & $\begin{array}{l}\text { Moderate-intensity statin therapy } \\
\text { group } \\
(n=1602)\end{array}$ & $\begin{array}{l}\text { High-intensity statin therapy } \\
\text { group } \\
(n=1284)\end{array}$ & $\begin{array}{l}p- \\
\text { value }\end{array}$ \\
\hline Age, year & $50 \pm 12$ & $53 \pm 8$ & $58 \pm 8$ & $<0.001$ \\
\hline Gender, male, n (\%) & $466(50.1)$ & $751(46.9)$ & $761(59.3)$ & $<0.776$ \\
\hline Hypertension, n (\%) & $272(29.2)$ & $488(30.5)$ & $493(38.4)$ & $<0.001$ \\
\hline Diabetes, n (\%) & $21(0.2)$ & $191(11.9)$ & $211(16.4)$ & $<0.001$ \\
\hline Dyslipidemia, n (\%) & $136(14.6)$ & $194(12.1)$ & $242(18.8)$ & $<0.001$ \\
\hline Familial history of CVA, $n(\%)$ & $121(13.0)$ & $304(19.0)$ & $500(38.9)$ & 0.145 \\
\hline Body mass index, $\mathrm{kg} / \mathrm{m}^{2}$ & $24.1 \pm 3.8$ & $24.6 \pm 3.6$ & $25.4 \pm 3.0$ & $<0.001$ \\
\hline Waist circumference, $\mathrm{cm}$ & $85 \pm 9$ & $87 \pm 9$ & $90 \pm 9$ & $<0.001$ \\
\hline Systolic BP, mm Hg & $120 \pm 13$ & $122 \pm 13$ & $128 \pm 14$ & $<0.001$ \\
\hline Diastolic BP, mm Hg & $120 \pm 13$ & $72 \pm 9$ & $77 \pm 10$ & $<0.001$ \\
\hline Heart rate, beats per minute & $62 \pm 8$ & $64 \pm 9$ & $64 \pm 10$ & 0.206 \\
\hline Smoking status, n (\%) & $308(33.1)$ & $144(9.0)$ & $537(41.8)$ & $<0.001$ \\
\hline Total cholesterol, mg/dL & $138 \pm 19$ & $201 \pm 32$ & $209 \pm 39$ & $<0.001$ \\
\hline Triglyceride, mg/dL & $148 \pm 16$ & $106 \pm 75$ & $141 \pm 86$ & $<0.001$ \\
\hline $\mathrm{HDL}-\mathrm{C}, \mathrm{mg} / \mathrm{dL}$ & $50 \pm 14$ & $54 \pm 13$ & $47 \pm 10$ & $<0.001$ \\
\hline $\mathrm{LDL}-\mathrm{C}, \mathrm{mg} / \mathrm{dL}$ & $59 \pm 11$ & $122 \pm 28$ & $130 \pm 35$ & $<0.001$ \\
\hline $\begin{array}{l}\text { Fasting blood glucose, mg/ } \\
\mathrm{dL}\end{array}$ & $91 \pm 14$ & $98 \pm 24$ & $105 \pm 28$ & $<0.001$ \\
\hline $\mathrm{HbA} 1 \mathrm{c}, \%$ & $5.5 \pm 0.4$ & $5.7 \pm 0.8$ & $5.9 \pm 0.9$ & $<0.001$ \\
\hline Fasting insulin, IU/L & $8.8 \pm 7.0$ & $8.0 \pm 5.2$ & $9.1 \pm 6.5$ & 0.246 \\
\hline HOMA-IR, & $1.9 \pm 2.3$ & $2.0 \pm 1.6$ & $2.4 \pm 2.1$ & 0.104 \\
\hline $\mathrm{C}$ reactive protein, $\mathrm{mg} / \mathrm{dL}$ & $0.11 \pm 0.37$ & $0.17 \pm 0.56$ & $0.18 \pm 0.44$ & 0.099 \\
\hline Ten-year, ASCVDS, \% & $2.1 \pm 2.0$ & $2.9 \pm 1.9$ & $12.6 \pm 5.3$ & $<0.001$ \\
\hline CACS & $2 \pm 8$ & $3 \pm 2$ & $98 \pm 270$ & $<0.001$ \\
\hline
\end{tabular}

Data are expressed as means \pm standard deviation

CVA cerebrovascular accident, BP blood pressure, HDL-C high-density lipoprotein cholesterol, LDL-C low-density lipoprotein cholesterol, HOMA-IR homeostasis model assessment insulin resistance, CAC coronary artery calcium, ASCVD atherosclerotic cardiovascular disease
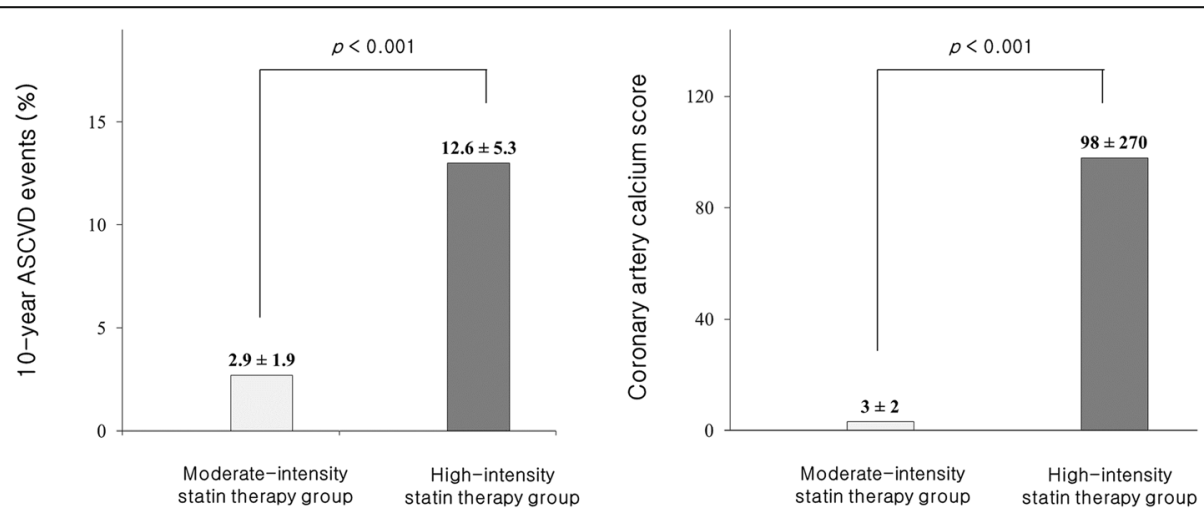

Fig. 1 Comparison of 10-year ASCVD event and CACS between two statin benefit groups* based on statin-intensity class of drug. *Statin benefit group was defined as individuals who can be considered moderate- and high-intensity statin therapy. ASCVD: atherosclerotic cardiovascular disease; CACS: coronary artery calcium score 
$98 \pm 24 \mathrm{mg} / \mathrm{dL}, p<0.001)$ and HbA1c $(5.9 \pm 0.9 \%$ vs. $5.7 \pm 0.8 \%, p<0.001)$; and fasting insulin $(9.1 \pm 6.5 \mathrm{IU} / \mathrm{L}$ vs. $8.0 \pm 5.2 \mathrm{IU} / \mathrm{L}, p<0.001$ ) (Table 1 ). However, plasma HDL-C concentration $(47 \pm 10 \mathrm{mg} / \mathrm{dL}$ vs. $54 \pm 13 \mathrm{mg} /$ $\mathrm{dL}, p<0.001)$ was significantly lower in the highintensity statin therapy group than in the moderateintensity statin therapy group (Table 1). Ten-year $\operatorname{ASCVD}(12.6 \pm 5.3 \%$ vs. $2.9 \pm 1.9 \%, p<0.001)$ and CACS (98 \pm 270 vs. $3 \pm 2, p<0.001)$, which are important tools for risk stratification in asymptomatic individuals, were significantly higher in the high-intensity statin therapy group than in the moderate-intensity statin therapy group (Fig. 1).

\section{CACS in moderate- and high-intensity statin therapy groups}

In the moderate-intensity statin therapy group, CACS was positively correlated with age $(r=0.202, p<0.001)$ and 10-year ASCVD $(r=0.112, p<0.001$; Table 2$)$.

In the high-intensity statin therapy group, CACS was positively correlated with age $(r=0.216, p<0.001)$, systolic BP $(r=0.102, p<0.001)$, plasma total cholesterol $(r=0.127, p<0.001)$, LDL-C $(r=0.144, p<0.001)$, fasting blood glucose $(r=0.109, p<0.001)$, HbA1c $(r=0.179, p<0.001)$, and 10-year ASCVD $(r=0.254$, $p<0.001$; Table 2).

\section{Predictability of CACS $\geq \mathbf{3 0 0}$}

In the high-intensity statin therapy group, age [odds ratio: 1.299 (1.137-1.483), $p<0.001$ ], male gender [odds ratio: 44.252 (1.959-999.784), $p=0.001]$, and fasting blood glucose [odds ratio: 1.046 (1.007-1.087), $p=0.021]$ were independent risk factors associated with CACS $\geq 300$ on multivariate logistic regression analysis (Table 3). A $90.5 \mathrm{mg} / \mathrm{dL}$ cut-off value of LDL-C was found to have a sensitivity of $87.1 \%$ and a specificity of $74.0 \%$ for predicting the probability of CACS $\geq 300$ (Fig. 2).

\section{Discussion}

Recent guidelines published by the ACC/AHA in 2013 demonstrate the importance of the prevention of CVD by accurate identification of higher risk individuals for statin therapy and by prompt decision-making regarding statin-intensity class of drugs for those most likely to benefit $[4,5]$.

\section{Beneficial versus controversial effects of statin therapy}

Statins are inhibitors of 3-hydroxy-3-methylglutaryl coenzyme A (HMG-CoA) reductase. The ACC/AHA 2013 guideline to reduce CVD risk, derived from systematic reviews and meta-analysis of randomized controlled trials, recommends individualization of statin therapy $[4,5]$ as well as lifestyle modification (i.e., adhering to a heart-

Table 2 Correlation coefficients between CACS and clinical variables in two statin benefit groups ${ }^{\text {a }}$ based on statin-intensity class of drug

\begin{tabular}{|c|c|c|c|c|}
\hline \multirow[t]{2}{*}{ Total $=2886$} & \multicolumn{2}{|c|}{$\begin{array}{l}\text { Moderate-intensity statin therapy group } \\
(\mathrm{n}=1602)\end{array}$} & \multicolumn{2}{|c|}{$\begin{array}{l}\text { High-intensity statin therapy group } \\
(n=1284)\end{array}$} \\
\hline & Correlation & $p$-value & Correlation & $p$-value \\
\hline Age, year & 0.202 & $<0.001$ & 0.216 & $<0.001$ \\
\hline Body mass index, $\mathrm{kg} / \mathrm{m}^{2}$ & 0.013 & 0.595 & 0.012 & 0.684 \\
\hline Waist circumference, cm & 0.026 & 0.299 & 0.041 & 0.151 \\
\hline Systolic BP, mm Hg & 0.092 & $<0.001$ & 0.102 & $<0.001$ \\
\hline Diastolic BP, mm Hg & 0.051 & 0.042 & 0.012 & 0.674 \\
\hline Heart rate, beats per minute & 0.010 & 0.704 & 0.082 & 0.004 \\
\hline Total cholesterol, mg/dL & 0.049 & 0.053 & 0.127 & $<0.001$ \\
\hline Triglyceride, mg/dL & 0.026 & 0.310 & 0.012 & 0.677 \\
\hline $\mathrm{HDL}-\mathrm{C}, \mathrm{mg} / \mathrm{dL}$ & -0.010 & 0.699 & -0.006 & 0.835 \\
\hline $\mathrm{LDL}-\mathrm{C}, \mathrm{mg} / \mathrm{dL}$ & 0.061 & 0.016 & 0.144 & $<0.001$ \\
\hline Fasting blood glucose, mg/dL & 0.091 & $<0.001$ & 0.109 & $<0.001$ \\
\hline $\mathrm{HbA} 1 \mathrm{c}, \%$ & 0.097 & $<0.001$ & 0.179 & $<0.001$ \\
\hline Fasting insulin, IU/L & 0.006 & $<0.001$ & 0.012 & 0.709 \\
\hline HOMA-IR, & 0.033 & 0.224 & 0.034 & 0.281 \\
\hline $\mathrm{C}$ reactive protein, $\mathrm{mg} / \mathrm{dL}$ & 0.028 & 0.281 & 0.012 & 0.685 \\
\hline Ten-year ASCVDS, \% & 0.112 & $<0.001$ & 0.254 & $<0.001$ \\
\hline
\end{tabular}

${ }^{a}$ Statin benefit group was defined as individuals who should be considered moderate- and high-intensity statin therapy $C A C$ coronary artery calcium, $B P$ blood pressure, $H D L-C$ high-density lipoprotein cholesterol, $L D L-C$ low-density lipoprotein cholesterol, $H O M A$ - $I R$ homeostasis model assessment insulin resistance, $A S C V D$ atherosclerotic cardiovascular disease 
Table 3 Multivariate logistic regression analysis for independent risk factors associated with CACS $\geq 300$

\begin{tabular}{|c|c|c|c|c|c|c|}
\hline & Moderate-in & atin therapy gro & & High-intens & therapy group & \\
\hline & Odds ratio & $95 \% \mathrm{Cl}$ & $p$-value & Odds ratio & $95 \% \mathrm{Cl}$ & $p$-value \\
\hline Age & 1.206 & $0.990-1.470$ & 0.062 & 1.299 & $1.137-1.483$ & $<0.001$ \\
\hline Gender, male & 6.726 & $0.149-302.635$ & 0.326 & 44.252 & $1.959-999.784$ & 0.017 \\
\hline Body mass index & 0.834 & $0.491-1.415$ & 0.501 & 1.095 & $0.735-1.632$ & 0.655 \\
\hline Waist circumference & 0.984 & $0.841-1.150$ & 0.838 & 0.956 & $0.838-1.089$ & 0.498 \\
\hline Systolic BP & 1.015 & $0.901-1.144$ & 0.801 & 1.066 & 0.999-1.138 & 0.053 \\
\hline Diastolic BP & 1.027 & $0.884-1.194$ & 0.723 & 0.988 & 0.889-1.097 & 0.816 \\
\hline Heart rate & 0.969 & $0.901-1.097$ & 0.906 & 0.958 & $0.895-1.025$ & 0.215 \\
\hline Total cholesterol & 1.010 & $0.850-1.105$ & 0.635 & 1.056 & $0.978-1.139$ & 0.164 \\
\hline Triglyceride & 1.049 & $0.987-1.035$ & 0.385 & 0.990 & $0.973-1.007$ & 0.232 \\
\hline $\mathrm{HDL}-\mathrm{C}$ & 1.021 & $0.900-1.221$ & 0.542 & 0.901 & $0.800-1.015$ & 0.087 \\
\hline LDL-C & 0.977 & $0.893-1.168$ & 0.757 & 0.944 & $0.872-1.022$ & 0.155 \\
\hline Fasting blood glucose & 0.753 & $0.837-1.141$ & 0.773 & 1.046 & $1.007-1.087$ & 0.021 \\
\hline $\mathrm{HbA1c}$ & 1.734 & $0.087-6.551$ & 0.797 & 1.034 & $0.321-3.325$ & 0.956 \\
\hline Fasting insulin & 0.131 & $0.261-11.521$ & 0.569 & 1.525 & $0.931-2.499$ & 0.094 \\
\hline HOMA-IR & 1.279 & $0.000-377.759$ & 0.617 & 0.235 & $0.041-1.346$ & 0.104 \\
\hline $\mathrm{C}$ reactive protein & 0.879 & $0.809-2.024$ & 0.292 & 0.249 & $0.008-8.009$ & 0.432 \\
\hline Ten-year ASCVDS & 0.948 & $0.386-1.999$ & 0.758 & 0.967 & $0.831-1.127$ & 0.669 \\
\hline
\end{tabular}

*Statin benefit group was defined as individuals who should be considered moderate- and high-intensity statin therapy

$C A C$ coronary artery calcium, $C l$ confidence intervals, BP blood pressure, $H D L-C$ high-density lipoprotein cholesterol, $L D L-C$ low-density lipoprotein cholesterol, HOMA-IR homeostasis model assessment insulin resistance, ASCVD atherosclerotic cardiovascular disease

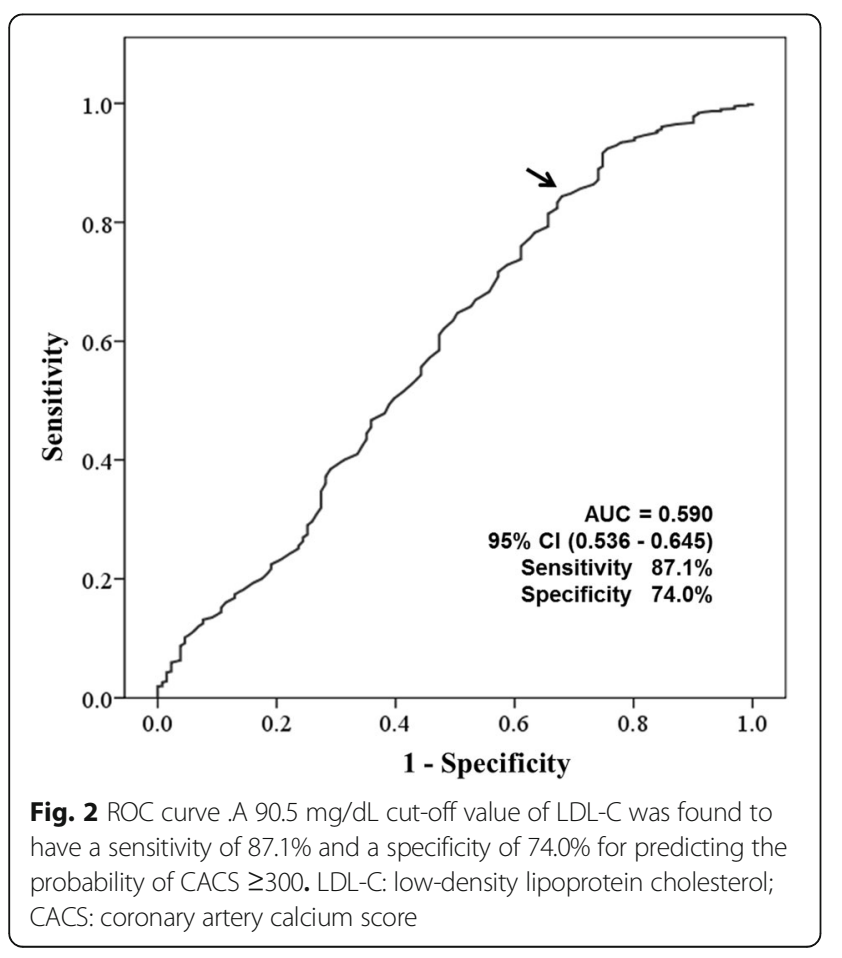

healthy diet, regular exercise habits, avoidance of tobacco products, and maintenance of a healthy weight) [14]. In the present study, we found $90.5 \mathrm{mg} / \mathrm{dL}$ LDL-C to have a high sensitivity and specificity for predicting the probability of a CACS $>300$ on MDCT. However, the role of blood cholesterol levels in CHD and the efficacy of cholesterol-lowering statin therapy remain controversial $[15,16]$.

In addition, this guideline concluded that statin therapy had no benefit on CHD mortality in a high-risk primary prevention population $[4,5]$. However, in recent meta-analysis of the benefits of statin, Savarese et al. showed that statin therapy reduces all-cause mortality and cardiovascular events in elderly people without established CVD [17]. Furthermore, in a meta-analysis of Cholesterol Treatment Trialists' Collaboration, although Fulcher et al. demonstrated that statin therapy was clearly beneficial in reducing cardiovascular events [18], Abramson et al. showed no benefit in terms of mortality outcomes [19].

\section{Diabetes is associated with statin therapy in asymptomatic individuals}

Diabetes, as a CVD "risk equivalent" and considered more aggressive lipid-lowering therapy, is associated with a marked increase in the risk of cardiovascular 
events, leading to MI, stroke and CHD-related death [12].

Nevertheless, in a multicenter, observational study, Dormuth et al. suggested that higher potency statin treatment is associated with increased risk of new-onset diabetes compared to lower potency statin treatment [20]. Although meta-analyses of clinical trial data revealed that increased risk of new-onset diabetes associated with statin therapy and statin use prior to diagnosis of new-onset diabetes do not increase the prevalence of microvascular disease, Betteridge et al. emphasized that statin-treated patients at high risk of developing diabetes should be monitored regularly for changes in blood glucose and HbA1c levels [21].

The present study demonstrated that diabetes is an independent risk factor associated with CACS $\geq 300$ on MDCT and plays an important role in coronary artery calcification in asymptomatic middle-aged individuals, especially in those requiring high-intensity statin therapy. Further investigation is needed in larger populations via multicenter trials to predict major adverse cardiovascular events and establish the role of diabetes as a cardiovascular disease "risk equivalent" in asymptomatic individuals.

\section{Limitations}

Our study has several limitations. In particular, the following elements were omitted: (i) cost-benefit evaluation of statin therapy; (ii) additional consideration of other factors such as apolipoprotein B, glomerular filtration rate, microalbuminuria, ankle-brachial index and carotid intima-media thickness; (iii) subgroup analysis such as racial, regional and gender differences; and (iv) analysis of secondary prevention in patients with established ASCVD.

\section{Conclusion}

In summary, CACS using MDCT might be an important complementary tool for CVD risk stratification. This study indicates that individualization of statin therapy as well as lifestyle modification will be useful in asymptomatic individuals, especially those in whom high-intensity statin therapy is required. In addition, further research on clinical outcomes is needed.

\footnotetext{
Abbreviations

ACC: American College of Cardiology; AHA: American heart Association; ASCVD: Atherosclerotic cardiovascular disease; BMI: Body mass index; BP: Blood pressure; CACS: Coronary artery calcium score; CHD: Coronary heart disease; Cl: Confidence intervals; CVA: Cerebrovascular accident; CVD: Cardiovascular disease; HDL-C: High-density lipoprotein cholesterol; HOMA-IR: Homeostasis model assessment insulin resistance; LDL-C: Lowdensity lipoprotein cholesterol; MDCT: Multidetector computed tomography; Ml: Myocardial infarction
}

\section{Acknowledgments}

The authors thank all the participants as well as the faculty \& staff - division of cardiology and radiology at the Health Promotion and Cardiovascular Center of Seoul St. Mary's Hospital (The Catholic University of Korea) for their cooperation in this study.

\section{Funding}

The authors declare that no competing financial interests exist.

Availability of data and materials

Not applicable.

\section{Data sharing statement}

No additional data are available.

\section{Authors' contributions}

$L D$ and $Y H$ designed the study, performed the experiments, analyzed the results and wrote the manuscript. $\mathrm{JH}, \mathrm{CK}, \mathrm{CY}$ and $\mathrm{JJ}$ contributed data analysis. All authors read and approved the final manuscript.

\section{Ethics approval and consent to participate}

This study was approved by the Institutional Review Committee of St Mary's Hospital, the Catholic University of Korea and conducted in agreement with the Declaration of Helsinki (KC17RESE0408).

Consent for publication

Not applicable.

\section{Competing interests}

The authors declare that they have no competing interests.

\section{Publisher's Note}

Springer Nature remains neutral with regard to jurisdictional claims in published maps and institutional affiliations.

\section{Author details}

'Division of Cardiology, Department of Internal Medicine, Seoul St. Mary's Hospital, The Catholic University of Korea, \#505 Banpo-dong, Seocho-gu, Seoul 137-701, South Korea. ${ }^{2}$ Division of Cardiology, Department of Radiology, Seoul St. Mary's Hospital, The Catholic University of Korea, \#505 Banpo-dong, Seocho-gu, Seoul 137-701, South Korea.

Received: 14 February 2017 Accepted: 4 September 2017 Published online: 12 September 2017

\section{References}

1. Kim J, Han HR. Physical activity, abdominal obesity and the risk of coronary heart disease: a Korean national sample study. Public Health. 2012;126(5): 410-6.

2. Brindle P, Emberson J, Lampe F, Walker M, Whincup P, Fahey T, et al. Predictive accuracy of the Framingham coronary risk score in British men: prospective cohort study. BMJ. 2003:327(7426):1267.

3. Brindle P, Beswick A, Fahey T, Ebrahim S. Accuracy and impact of risk assessment in the primary prevention of cardiovascular disease: a systematic review. Heart. 2006;92(12):1752-9.

4. Goff DC Jr, Lloyd-Jones DM, Bennett G, Coady S, D'Agostino RB Sr, Gibbons R, et al. 2013 ACC/AHA guideline on the assessment of cardiovascular risk: a report of the American College of Cardiology/ American Heart Association task force on practice guidelines. J Am Coll Cardiol. 2014;63(25 Pt B):2935-59.

5. Stone NJ, Robinson JG, Lichtenstein AH, Bairey Merz CN, Blum CB, Eckel RH, et al. 2013 ACC/AHA guideline on the treatment of blood cholesterol to reduce atherosclerotic cardiovascular risk in adults: a report of the American College of Cardiology/American Heart Association task force on practice guidelines. J Am Coll Cardiol. 2014:63(25 Pt B):2889-934.

6. Greenland P, Alpert JS, Beller GA, Benjamin EJ, Budoff MJ, Fayad ZA, Foster E, et al. 2010 ACCF/AHA guideline for assessment of cardiovascular risk in asymptomatic adults: a report of the American College of Cardiology Foundation/American Heart Association task force on practice guidelines. J Am Coll Cardiol. 2010;56(25):e50-103. 
7. Taylor AJ, Cerqueira M, Hodgson JM, Mark D, Min J, O'Gara P, et al. ACCF/ SCCT/ACR/AHA/ASE/ASNC/NASCI/SCAI/SCMR 2010 appropriate use criteria for cardiac computed tomography. A report of the American College of Cardiology Foundation appropriate use criteria task force, the Society of Cardiovascular Computed Tomography, the American College of Radiology, the American Heart Association, the American Society of Echocardiography, the American Society of Nuclear Cardiology, the north American Society for Cardiovascular Imaging, the Society for Cardiovascular Angiography and Interventions, and the Society for Cardiovascular Magnetic Resonance. J Am Coll Cardiol. 2010;56(22):1864-94.

8. Budoff MJ, Achenbach S, Blumenthal RS, Carr JJ, Goldin JG, Greenland P, et al. Assessment of coronary artery disease by cardiac computed tomography: a scientific statement from the American Heart Association Committee on cardiovascular imaging and intervention, council on cardiovascular radiology and intervention, and committee on cardiac imaging. Counc Clin Cardiol Circ. 2006;114(16):1761-91.

9. Hamon M, Biondi-Zoccai GG, Malagutti P, Agostoni P, Morello R, Valgimigli $M$, et al. Diagnostic performance of multislice spiral computed tomography of coronary arteries as compared with conventional invasive coronary angiography: a meta-analysis. J Am Coll Cardiol. 2006;48(9):1896-910.

10. Arad Y, Goodman KI, Roth M, Newstein D, Guerci AD. Coronary calcification, coronary disease risk factors, C-reactive protein, and atherosclerotic cardiovascular disease events: the St. Francis study J Am Coll Cardiol. 2005; 46(1):158-65.

11. Elias-Smale SE, Proença RV, Koller MT, Kavousi M, van Rooij FJ, Hunink MG, et al. Coronary calcium score improves classification of coronary heart disease risk in the elderly: the Rotterdam study. J Am Coll Cardiol. 2010; 56(17):1407-14.

12. National Cholesterol Education Program (NCEP) Expert Panel on Detection, Evaluation, and Treatment of High Blood Cholesterol in Adults (Adult Treatment Panel III). Third report of the National Cholesterol Education Program (NCEP) expert panel on detection, evaluation, and treatment of high blood cholesterol in adults (adult treatment panel III) final report. Circulation. 2002;106(25):3143-421.

13. Agatston AS, Janowitz WR, Hildner FJ, Zusmer NR, Viamonte M Jr, Detrano R. Quantification of coronary artery calcium using ultrafast computed tomography. J Am Coll Cardiol. 1990;15(4):827-32.

14. Eckel RH, Jakicic JM, Ard JD, de Jesus JM, Houston Miller N, Hubbard VS, et al. 2013 AHA/ACC guideline on lifestyle management to reduce cardiovascular risk: a report of the American College of Cardiology/ American Heart Association task force on practice guidelines. J Am Coll Cardiol. 2014;63(25 Pt B):2960-84.

15. DuBroff R, de Lorgeril M. Cholesterol confusion and statin controversy. World J Cardiol. 2015;7(7):404-9.

16. Smith SC Jr, Grundy SM. Reply: Statin dose based on limited evidence. J Am Coll Cardiol. 2015;65(7):760-1.

17. Savarese G, Gotto AM Jr, Paolillo S, D'Amore C, Losco T, Musella F, et al. Benefits of statins in elderly subjects without established cardiovascular disease: a meta-analysis. J Am Coll Cardiol. 2013;62(22):2090-9.

18. Cholesterol Treatment Trialists' (CTT) Collaboration, Fulcher J, O'Connell R, Voysey M, Emberson J, Blackwell L, Mihaylova B, et al. Efficacy and safety of LDL-lowering therapy among men and women: meta-analysis of individual data from 174,000 participants in 27 randomised trials. Lancet. 2015; 385(9976):1397-405.

19. Abramson JD, Rosenberg HG, Jewell N, Wright JM. Should people at low risk of cardiovascular disease take a statin? BMJ. 2013;347:f6123.

20. Dormuth CR, Filion KB, Paterson JM, James MT, Teare GF, Raymond CB, et al. Higher potency statins and the risk of new diabetes: multicentre, observational study of administrative databases. BMJ. 2014;348:93244.

21. Betteridge DJ, Carmena R. The diabetogenic action of statins - mechanisms and clinical implications. Nat Rev Endocrinol. 2016;12(2):99-110.

\section{Submit your next manuscript to BioMed Central and we will help you at every step:}

- We accept pre-submission inquiries

- Our selector tool helps you to find the most relevant journal

- We provide round the clock customer support

- Convenient online submission

- Thorough peer review

- Inclusion in PubMed and all major indexing services

- Maximum visibility for your research

Submit your manuscript at www.biomedcentral.com/submit
Biomed Central 